\title{
Sound Processor Replacement in Patients with Cochlear Implant: Analysis of a 30-Year Single-Institutional Experience
}

\author{
Myung Jin Lee, Seung Eun Lee, Jae Yeon Mun, and Kyu-Yup Lee ${ }^{\mathbb{D}}$ \\ Department of Otorhinolaryngology-Head and Neck Surgery, Kyungpook National University Hospital, Daegu, Korea
}

인공와우 외부 음향처리기 교체에 대한 분석: 30 년간의 경험

이명진 · 이승은 · 문재연 · 이규엽

경북대학교병원 이비인후과

Received June 23, 2020

Revised September 11, 2020

Accepted September 28, 2020

Address for correspondence

Kyu Yup Lee, MD, PhD

Department of Otorhinolaryngology-

Head and Neck Surgery,

Kyungpook National

University Hospital,

130 Dongdeok-ro, Jung-gu,

Daegu 41944, Korea

Tel +82-53-200-5784

Fax +82-53-200-4524

E-mail kylee@knu.ac.kr
Background and Objectives The purpose of this study is to investigate the replacement of external sound processors and to help understand the economic burden experienced from cochlear implant users.

Subjects and Method Among the 500 cases of cochlear implant surgery from 1992 to 2019, 336 cases from 311 patients who had used a cochlear implant for more than 1 year were enrolled. The period of cochlear implant use, replacement of the sound processor, the number, method, and reason of replacements were examined.

Results One hundred sixty cases (47.62\%) replaced the sound processor at least once. There were a total of 213 replacements made in 160 cases. The most common reason for replacing the sound processors was because it could not be repaired ( 71 replacements, 33.33\%), with their period of use being an average of 12 years. The most common replacement method of the sound processors was by purchasing with medical insurance benefits (100 replacements, $46.95 \%$ ), with the usage period being an average of 11 years and 4 months.

Conclusion Cochlear implant users replaced the sound processor for various reasons and the period of using one sound processor was relatively short. About half of all replacement cases were made by applying for medical insurance benefits. Others purchased directly through a sales company and paid a relatively high cost. Therefore, it is necessary to expand the medical insurance for external sound processor of cochlear implants to include exchange times considering the economic burden of cochlear implant users.

Korean J Otorhinolaryngol-Head Neck Surg 2021;64(7):467-72

Key Words Cochlear implant $\cdot$ External device $\cdot$ Failure rate $\cdot$ Hearing loss.

\begin{abstract}
서 론
인공와우는 보청기를 통해 큰 이득을 얻을 수 없는 고심도 의 청각 장애인에게 이식된 전극을 통해 청신경을 자극하여 뇌에서 소리를 인지하도록 돕는 청각재활 방법이다. 국내에서

This is an Open Access article distributed under the terms of the Creative Commons Attribution Non-Commercial License (https://creativecommons.org/licenses/by-nc/4.0) which permits unrestricted non-commercial use, distribution, and reproduction in any medium, provided the original work is properly cited.
\end{abstract}

는 1988년부터 현재까지 약 30년 동안 인공와우 이식이 이루 어지고 있다. ${ }^{1)}$ 인공와우는 기술의 발전과 함께 의료급여 선정 및 급여 기준의 변화로 인해 영유아에서 노년층까지 이식 연 령이 확대되었고 편측에서 양측으로 이식 범위도 확대되었다.

2000년대초부터 신생아 청력 선별검사가 시행되어 인공와 우 대상자가 조기에 발견되었고, 다양한 연구들에서 인공와 우의 효과가 입증되었다. ${ }^{2-5)}$ 또한 양측 인공와우의 이득에 대 한 연구 결과가 꾸준히 보고되면서 최근에는 동시 양측 인공 
와우 이식이 영유아에서 일반적으로 시행되고 있고 성인에서 도 양측 인공와우를 시행하거나 고려하는 추세이다. ${ }^{6-8)}$

그러나 인공와우 이식으로 청각적 이득이 있음에도 불구 하고 인공와우 사용자들의 인공와우를 사용하고 유지함에 있어 발생하는 비용에 대한 부담은 날로 증가하고 있다.' ${ }^{9}$ 한 번에 가장 많은 비용이 발생하는 부분이 외부 음향처리기의 교체이다. 인공와우의 외부 음향처리기는 소리를 받아들여 디지털 신호로 변환하고, 그 신호를 체내에 이식된 임플란트 로 전달하는 기능을 한다. 그러나 땀, 습기 등의 지속적인 노 출에 약하고 이로 인해 수리가 불가능한 중요한 전자부품들 이 손상되기 쉽지만 무료로 수리 및 교환 받을 수 있는 제조 사별로 보증기간은 3 5년으로 길지 않다. 또한 관련된 다양 한 부품들은 제조회사의 생산 및 판매 기간에 따라 수리와 구입이 불가능해지기도 한다.

인공와우는 2005년부터 편측에 의료 급여가 적용되기 시 작하여 2009년에는 15세 미만에서 양측 인공와우 의료급여 적용으로 확대되었고 2017년에는 양측 인공와우 의료급여 적용 기준이 19 세 미만으로 개정되어 인공와우 의료급여 범 위가 점차 확대되었다. ${ }^{10)}$ 음향처리기에 대한 추가 급여 인정 개수도 2009년에 편측 인공와우 이식자일 경우 하나가 추가 로 인정되었고 2018년에는 양측 인공와우 이식자에서도 추 가로 두 개까지 급여 혜택을 받을 수 있도록 개정되었다.

지금까지 인공와우의 내부기의 고장에 대한 논문은 국내 외에 많이 있지만,11,12) 외부 음향처리기의 교체에 대한 연구 논문은 전세계적으로 찾아보기 어렵다. 따라서 이 연구를 통 해 인공와우 사용자들이 하나의 외부 음향처리기를 사용하 는 기간이 실제로 어느 정도이고 교체는 어떻게 이루어지고 있는지 알아보고, 향후 인공와우를 사용하고 유지하는 데 예 상되는 경제적, 사회적 영향과 인공와우의 기계적 개선과 인 공와우 관련 보험 규정에 대한 합리적 개선에 대해 논의하고 자 한다.

\section{대상 및 방법}

\section{연구 대상}

이 연구는 1992년부터 2019년 12월까지 경북대학교병원에 서 시행한 인공와우 이식 수술 약 500예 중에서 최근 5년동 안 한번 이상 내원하였고 인공와우 착용 기간이 1년 이상 된 환자 311명(남 144명, 여 167명)의 336예를 대상으로 하였다. 한 귀를 한 예로 하여 222예는 Cochlear Ltd.(Sydney, Australia), 105예는 MED-EL(Innsbruck, Austria), 9예는 Advanced Bionics(Zürich, Switzerland) 제품이었다. 연구 대 상에 대한 일반적인 정보를 전체와 인공와우 착용 기간별로
나누어 Table 1에 제시하였다.

\section{연구 절차}

음향처리기의 사용 및 교체와 관련된 정보를 확인하기 위 해서 1 차로 의무기록을 분석하였고, 부족한 정보에 대해서는 2차로 환자나 보호자, 관련 기관을 통해 설문조사를 실시하 였다. 의무기록 및 환자 정보 사용과 관련하여 본 연구는 인 증된 연구윤리 심의위원회의 승인을 받았다(KHUH 202007-019-002).

\section{자료 분석 및 처리}

음향처리기의 사용 기간은 하나의 음향처리기의 첫 착용일 로부터 새로운 음향처리기로 교체하기 전일까지로 하고, 계산 된 기간에서 개월 수까지를 '사용 기간'으로 하였다. 모든 자 료는 한 귀에 대한 사례별로 분석하였고 양측 인공와우 사용 자는 양이 각각에 대해 분석하였다.

음향처리기의 사용 기간이 교체 원인과 교체 방법에 따라 차이를 보이는지 알아보기 위해 일원배치 분산분석(one-way analysis of variance)을 실시하였고, 각 집단 간 평균을 비교 하기 위해 Scheffe 사후검정 또는 Games-Howell 사후검정 을 실시하였다. 모든 자료의 통계처리는 SPSS 22.0 프로그램 (IBM Corp., Armonk, NY, USA)을 사용하였다.

\section{결 과}

\section{음향처리기 교체율과 교체 빈도}

전체 336예에서 절반 정도인 160예(47.62\%)가 1회 이상 음 향처리기를 교체하였다. 그 중에서도 113예(33.63\%)는 1회, 41예(12.20\%)는 2회, 6예(1.79\%)는 3회 교체하여 160예에서 총 213건의 교체가 있었다(Fig. 1). 인공와우 착용 기간을 5년 단위로 나누어 분석한 결과, 인공와우 착용 기간이 긴 집단 일수록 교체율이 높고 교체 빈도도 증가하였다(Table 2). 인 공와우 착용 기간이 11년 이상 15 년 이하인 집단에서 교체율 $50 \%$ 를 넘기기 시작해서 16 년 이상인 두 집단에서는 한 명을 제외하고 모두 1 회 이상 음향처리기를 교체하였다. 또한 인공 와우 착용 기간이 비교적 짧은 6년 이상인 집단에서 2회 이 상의 교체가 나타나기 시작해서 16년 이상의 두 집단에서는 $50 \%$ 이상이 2회 이상 음향처리기를 교체한 것으로 나타났다. 3 회 교체한 6 예는 모두 16년 이상 된 인공와우 사용자로 모 두 ‘박스형-귀걸이형-귀걸이형-일체형' 순서로 교체하여 사 용 중이었다. 


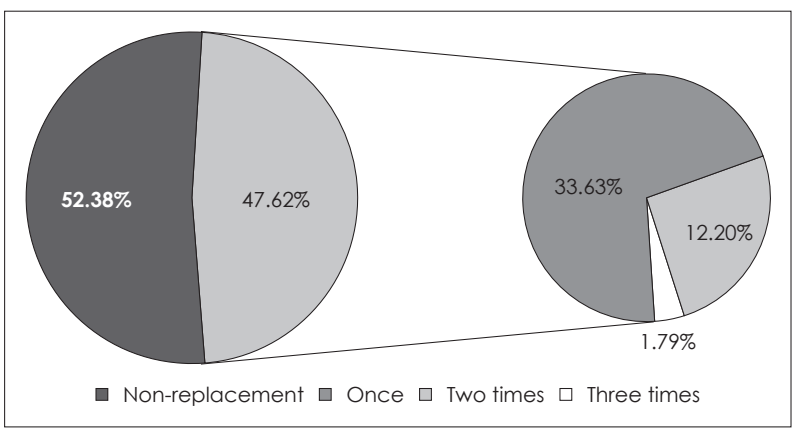

Fig. 1. Replacement rate of sound processor.

\section{음향처리기 사용 기간}

\section{교체 원인에 따른 사용 기간}

음향처리기를 교체한 이유는 1) 음향처리기의 수리 불가능 한 부분(인쇄 회로 기판, printed circuit board)이 손상되었 거나, 음향처리기의 일부가 손상되었으나 서비스 종료로 인해 구입하거나 수리 받지 못한 경우(수리불가판정), 2) 음향처리 기 노후, 3) 지금보다 더 잘 듣고 싶어서, 4) 음향처리기의 착용 편의성을 위해서(박스형에서 귀걸이형으로, 귀걸이형에서 일 체형으로 교체한 경우), 5) 음향처리기 분실, 6) 내부 임플란 트 교체나 고장으로 인해 재수술을 받으면서, 7) 순차적 양측 인공와우 이식 수술로 기존에 사용하던 음향처리기를 교체 받아서 등의 7가지 이유로 분류되었다. 이러한 교체 이유들 중에서 수리 불가한 이유가 전체의 $33.33 \%$ (71건)로 가장 높 은 비율을 차지하였고 음향처리기의 착용 편의성 $(26.29 \%, 56$ 건), 분실(14.55\%, 31건), 노후(11.27\%, 24건), 더 잘 듣고 싶어 서(9.86\%, 21건), 재수술( $2.82 \%, 6$ 건), 순차적 양측 인공와우 수술(1.88\%, 4건) 등의 이유가 그 뒤를 따랐다(Table 3).

총 213건의 교체에서 하나의 음향처리기를 사용한 기간은 평균 8년 4개월로 나타났다. 노후로 인한 교체 시 음향처리기 사용 기간은 평균 12 년 11 개월로 가장 길었다. 그 다음으로는 수리 불가로 인한 교체에서 평균 12년, 분실로 인한 교체에서 평균 9년 5개월, 순차적 양측 인공와우 수술과 관련된 교체 에서 평균 8년 7개월, 재수술로 인한 교체에서 평균 7년 11개 월, 더 잘 듣기 위한 교체에서 평균 5 년 1 개월, 편의성을 위 한 교체에서 평균 2년 5개월로 가장 짧게 나타났다(Table 3 , Fig. 2).

음향처리기를 교체한 이유에 따라 사용 기간에 차이를 보 이는지 알아보기 위해 일원배치 분산분석을 실시한 결과, 집 단 간에 유의한 차이를 보였다 $(\mathrm{F}=65.035, p<0.001)$. 집단 간 음향처리기 사용 기간의 차이를 알아보기 위해 Scheffe 사후 검정을 실시한 결과, 수리 불가하여 교체한 집단과 더 잘 듣기 위해 교체한 집단 $(p<0.001)$, 수리 불가하여 교체한 집단과 편 
Table 2. Replacement rate of sound processor according to the duration of cochlear implantation

\begin{tabular}{lccccc}
\hline & $1-5 y$ & $6-10 y$ & $11-15 y$ & $16-20 y$ & $\geq 21 y$ \\
\hline Replacement rate (cases) & $2.52(3 / 116)$ & $31.88(22 / 69)$ & $80.77(63 / 78)$ & $98.48(65 / 66)$ & $100(7 / 7)$ \\
Number of replacement times (cases) & & & & & \\
$\quad$ Once & $100(3 / 3)$ & $86.36(19 / 22)$ & $90.48(57 / 63)$ & $49.23(32 / 65)$ & $28.57(2 / 7)$ \\
$\quad$ Two times & - & $13.64(3 / 22)$ & $9.52(6 / 63)$ & $43.08(28 / 65)$ & $57.14(4 / 7)$ \\
$\quad$ Three times & - & - & - & $7.69(5 / 65)$ & $14.29(1 / 7)$ \\
\hline
\end{tabular}

Data are presented as \%. y: year

Table 3. Period of use of sound processor according to the reason for replacement

\begin{tabular}{lccc}
\hline & Number (cases, \%) & Period of use & Range \\
\hline Unrepairable & $71(33.33)$ & 12 y \pm 3 y $7 \mathrm{~m}$ & 3 y $5 \mathrm{~m}-22$ y $10 \mathrm{~m}$ \\
Aging & $24(11.27)$ & 12 y $11 \mathrm{~m} \pm 2$ y $4 \mathrm{~m}$ & 9 y $9 \mathrm{~m}-18$ y $11 \mathrm{~m}$ \\
To hear better & $21(9.86)$ & 5 y $1 \mathrm{~m} \pm 2$ y $8 \mathrm{~m}$ & $3 \mathrm{~m}-8$ y $7 \mathrm{~m}$ \\
Convenience & $56(26.29)$ & 2 y $5 \mathrm{~m} \pm 2$ y $7 \mathrm{~m}$ & $3 \mathrm{~m}-11$ y $6 \mathrm{~m}$ \\
Lost & $31(14.55)$ & 9 y $5 \mathrm{~m} \pm 3$ y $3 \mathrm{~m}$ & 2 y $7 \mathrm{~m}-17$ y \\
Revision surgery & $6(2.82)$ & 7 y $11 \mathrm{~m} \pm 3$ y $11 \mathrm{~m}$ & 2 y $7 \mathrm{~m}-13$ y $3 \mathrm{~m}$ \\
Sequential cochlear implantation & $4(1.88)$ & 8 y $7 \mathrm{~m} \pm 1$ y $11 \mathrm{~m}$ & 6 y $2 \mathrm{~m}-10$ y $3 \mathrm{~m}$ \\
Total & $213(100)$ & 8 y $4 \mathrm{~m} \pm 5$ y $2 \mathrm{~m}$ & $3 \mathrm{~m}-22$ y $10 \mathrm{~m}$ \\
\hline
\end{tabular}

The values indicate the average \pm standard deviation. $y$ : year, $\mathrm{m}$ : month

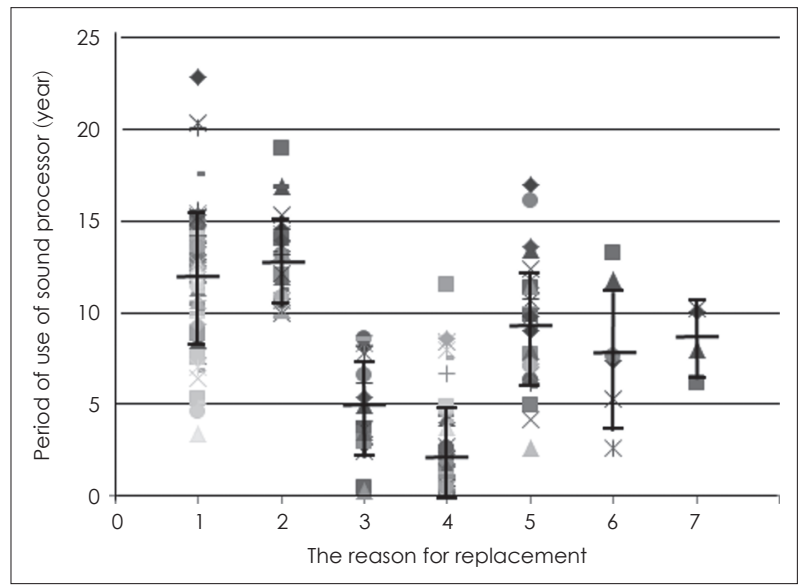

Fig. 2. Period of use of sound processor according to the reason for replacement. 1: unrepairable, 2: aging, 3: to hear better, 4: convenience, 5: lost, 6: revision surgery, 7: sequential cochlear implantation.

의성을 위해 교체한 집단 $(p<0.001)$, 수리 불가한 집단과 분 실로 인해 교체한 집단 $(p<0.01)$, 노후로 인해 교체한 집단과 더 잘 듣기 위해 교체한 집단 $(p<0.001)$, 노후로 인해 교체한 집단과 편의성을 위해 교체한 집단 $(p<0.001)$, 노후로 인해 교체한 집단과 분실로 인해 교체한 집단 $(p<0.01)$, 더 잘 듣기 위해 교체한 집단과 분실로 인해 교체한 집단 $(p<0.01)$, 편의 성을 위해 교체한 집단과 분실로 인한 집단 $(p<0.001)$, 편의성 을 위해 교체한 집단과 재수술로 인한 교체한 집단 $(p<0.01)$, 편의성을 위해 교체한 집단과 순차 양측 인공와우 수술로 인 해 교체한 집단 $(p<0.05)$ 사이에 유의미한 차이가 있는 것으 로 나타났다. 사용 기간은 수리불가나 노후로 인해 음향처리
기를 교체한 경우가 더 잘 듣기 위해서, 편의성, 분실로 인해 교체한 경우보다 유의하게 길었다. 특히 편의성이나 더 잘 듣 기 위해 교체한 경우는 다른 이유들에서보다 음향처리기의 사용 기간이 유의하게 짧은 것으로 나타났다.

\section{교체 방법에 따른 사용 기간}

음향처리기의 교체 방법은 1) 수리 불가나 분실로 인해 의 료급여 적용을 받아서 구입하거나, 2) 판매회사를 통해 전액 또는 할인된 금액으로 직접 구입하거나, 3) 온라인이나 지인을 통해 중고로 구입하거나, 4) 판매회사의 무료 교환 프로모션 이나 쿠폰 등으로 무료 교체 받는 등 네 가지 방법으로 분류 되었다. 이러한 교체 방법들 중에서 의료급여 적용을 받아서 구입한 경우가 전체의 $46.95 \%$ (100건)로 가장 높은 비율을 차 지하였고 그 다음으로는 판매회사를 통한 직접 구입 $(27.23 \%$, 58건), 판매회사를 통한 무료 교체(23.94\%, 51건), 중고 구입 $(1.88 \%, 4$ 건 $)$ 등의 순서로 나타났다(Table 4).

의료급여 적용을 받아서 구입한 경우에 음향처리기 사용 기간은 평균 11 년 4 개월로 가장 길었다. 그 다음으로는 중고 로 구입한 경우에 평균 9년 9개월, 판매회사를 통해 직접 구 입한 경우에 평균 8년 10 개월, 판매회사를 통해 무료 교체 받 은 경우에 평균 1년 11 개월 사용하는 것으로 나타났다(Table 4, Fig. 3).

음향처리기를 교체한 방법에 따라 사용 기간에 차이를 보 이는지 알아보기 위해 일원배치 분산분석을 실시한 결과, 등 분산이 가정되지 않았다. 따라서 집단 간 음향처리기 사용 기 간의 차이를 알아보기 위해 Games-Howell 사후검정을 실 
Table 4. Period of use of sound processor according to the method of replacement

\begin{tabular}{lccc} 
& Number (cases, \%) & Period of use & Range \\
\hline Application of medical insurance benefits & $100(46.95)$ & 11 y $4 \mathrm{~m} \pm 3$ y $8 \mathrm{~m}$ & 2 y $7 \mathrm{~m}-22$ y $10 \mathrm{~m}$ \\
Direct purchase through the company & $58(27.23)$ & 8 y $10 \mathrm{~m} \pm 4$ y $1 \mathrm{~m}$ & 2 y $5 \mathrm{~m}-18$ y $11 \mathrm{~m}$ \\
Second-hand purchase & $4(1.88)$ & 9 y $9 \mathrm{~m} \pm 4$ y $7 \mathrm{~m}$ & 4 y-13 y $11 \mathrm{~m}$ \\
Free exchange through the company & $51(23.94)$ & 1 y $11 \mathrm{~m} \pm 5$ y $2 \mathrm{~m}$ & $3 \mathrm{~m}-10$ y $3 \mathrm{~m}$ \\
Total & $213(100)$ & 8 y $4 \mathrm{~m} \pm 5$ y $2 \mathrm{~m}$ & $3 \mathrm{~m}-22$ y $10 \mathrm{~m}$ \\
\hline
\end{tabular}

The values indicate the average \pm standard deviation. $y$ : year, $m$ : month

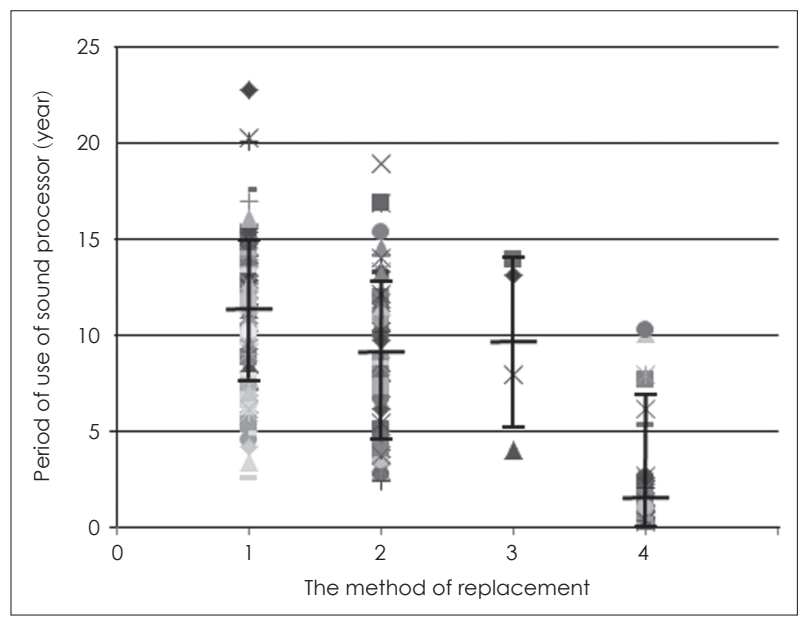

Fig. 3. Period of use of sound processor according to the method of replacement. 1: application of medical insurance benefits, 2 : direct purchase through the company, 3: second-hand purchase, 4: free exchange through the company.

시한 결과, 의료급여 적용을 받아서 구입한 집단과 판매회사 를 통해 직접 구입한 집단 $(p<0.01)$, 의료급여 적용을 받아서 구입한 집단과 판매회사를 통해 무료로 교환받은 집단 $(p<$ 0.001), 판매회사를 통해 직접 구입한 집단과 판매회사를 통 해 무료로 교환받은 집단 $(p<0.001)$ 사이에 유의미한 차이가 있는 것으로 나타났다. 사용 기간은 의료급여 적용을 받아서 구입한 경우가 판매회사를 통해 구입하거나 무료로 교환 받 았을 때보다 유의미하게 길었다. 또한 판매회사를 통해 무료 로 교환 받은 경우에 사용 시간이 유의미하게 짧은 것으로 나타났다.

\section{고 찰}

본 연구는 인공와우 사용자들의 외부음향처리기의 교체와 관련된 사용 기간, 원인 등을 알아보고 음향처리기의 교체율 과 교체 빈도, 교체 이유와 교체 이유에 따른 사용 기간, 교 체 방법과 교체 방법에 따른 사용 기간에 대해 분석하였다.

인공와우의 교체율은 전체 336예 중 47.62\%로 160 예가 1회 이상 교체하였고, 교체 빈도는 적게는 1 회에서 많게는 3 회로 총 213건의 교체를 확인하였다. 인공와우 착용 기간이 긴 집
단일수록 교체율과 교체 빈도가 높았다.

음향처리기를 교체한 이유로는 음향처리기의 수리가 불가 능한 부분의 손상이나 수리 서비스 종료로 인한 수리 불가한 경우가 전체의 $33.33 \%$ 로 가장 높게 나타났다. 그 다음으로 음 향처리기 착용 형태에 따른 편의성과 관련된 교체가 $26.29 \%$, 분실로 인한 교체가 $14.55 \%$, 노후화로 $11.27 \%$, 더 잘 듣고 싶 어서 $9.86 \%$, 재수술로 인한 교체가 $2.82 \%$, 순차적 양측 인공 와우 수술로 인한 교체가 $1.88 \%$ 로 나타났다. 음향처리기를 교체한 이유에 따른 음향처리기 사용 기간은 집단 사이에 유 의미한 차이가 있는 것으로 나타났다. 음향처리기를 교체한 이유들 중에서 가장 높은 비율을 차지했던 수리불가로 인한 교체와 노후로 인한 교체에서 사용 기간은 각각 평균 12년, 평균 12 년 11 개월로 가장 길었고, 편의성을 위한 교체에서 사 용 기간은 평균 2년 5개월로 가장 짧았다.

음향처리기의 교체 방법은 의료급여 적용을 받아서 구입한 경우가 전체의 $46.95 \%$ 로 가장 높게 나타났다. 그 다음으로는 판매회사를 통해 직접 구입하여 교체한 경우가 $27.23 \%$, 판매 회사를 통해 무료로 교체 받은 경우가 $23.94 \%$, 중고로 구입 한 경우가 $1.88 \%$ 로 나타났다. 음향처리기의 교체 방법에 따 른 음향처리기 사용 기간은 집단 간에 유의미한 차이가 있는 것으로 나타났다. 음향처리기를 교체한 방법들 중에서 가장 높은 비율을 차지했던 의료급여 적용을 받고 구입하여 교체 한 경우의 사용 기간은 평균 11 년 4 개월로 가장 길었고, 판매 회사를 통해 무료로 교환 받은 경우의 사용 기간은 평균 1년 11 개월로 가장 짧았다.

전체 대상 중에서 하나의 음향처리기를 가장 길게 사용한 1 예는 22년 10 개월이었고 관련 부속품 판매 종료와 관련된 수리 불가한 이유로 의료급여 적용을 받아서 구입, 교체하였 다. 가장 짧게 사용한 2예는 3 개월로 판매회사의 신제품 프 로모션 행사 기간에 착용 편의성이나 더 잘 듣기 위해서 무 료로 교환 받았다.

비교적 단기간에 음향처리기의 착용편의성이나 더 잘 듣기 위해서 교체한 사례들은 대부분 판매회사의 무료교체 프로 모션 행사와 관련되었다. 그 외에 음향처리기를 교체한 이유 들 중에 대부분은 수리 불가, 분실, 노후로 인한 교체였다. 이 
러한 이유로 인한 교체 시 사용 기간은 각각 평균 12 년, 평균 9년 5개월, 평균 12 년 11 개월이었다. 그 중 수리 불가와 분실 로 인한 교체는 의료급여 적용(1회)을 받아서 구입할 수 있다. 그러나 노후로 인한 교체는 의료급여 적용이 불가하여 상대 적으로 비용 부담이 컸을 것으로 예상되었다.

위의 연구 결과를 통해 판매회사의 프로모션 행사 등 특수 한 경우를 제외하고 하나의 음향처리기를 사용하는 기간은 평균 10 년 안팎인 것을 알 수 있었다. 또한 음향처리기를 20년 넘게 사용한 사례가 전체 213 건의 교체 중 3 건에 불과하다는 점에서 부속품 구입 등의 문제로 수리가 불가능해지기 전까 지 잘 사용하더라도 20년을 넘기기 힘든 것으로 결론 지을 수 있었다.

이러한 연구 결과를 통해 인공와우 음향처리기의 교체율이 높고 다양한 이유로 교체가 이루어지고 있으며 하나의 음향 처리기를 사용하는 기간이 생각보다 짧다는 것을 알 수 있었 다. 또한 의료급여 적용을 받기도 하지만 받지 못하는 구입도 많다는 것을 확인할 수 있었다. 우리나라에서 청각장애는 신 생아 약 1000 명당 1 3명에게 나타나는 것으로 알려져 있고, 인구의 고령화로 인해 보청기 사용자에서 인공와우 이식 대 상자도 점차 늘어날 것으로 예측하고 있다. ${ }^{13,14)}$ 현재 인공와우 이식수술은 고심도 청각장애의 일반적인 청각재활 방법으로 다양한 연령대에서 시행되고 있다. 이러한 시회적 변화에 맞 추어 인공와우 사용자들이 하나의 음향처리기를 일정 기간 동안 잘 사용하게 하면서도 더 잘 듣고 싶은 기본적인 욕구 를 고려하여 새로운 대책이나 지원에 대해서도 생각해봐야 할 것이다. 이 연구의 결과가 인공와우 사용자들의 지원을 결 정하는 데 기초 자료로 활용되기를 기대한다.

\section{Acknowledgments}

None.

\section{Author Contribution}

Conceptualization: Kyu-Yup Lee. Data curation: Myung Jin Lee. Formal analysis: Myung Jin Lee. Investigation: Kyu-Yup Lee. Methodology: Myung Jin Lee, Seung Eun Lee. Project administration: Kyu-Yup Lee. Resources: Kyu-Yup Lee. Visualization: Jae Yeon Mun. Writing — original draft: Myung Jin Lee, Kyu-Yup Lee. Writing — review \& editing: Myung Jin Lee, Kyu-Yup Lee.
ORCID

Kyu-Yup Lee ～https://orcid.org/0000-0001-7170-4847

\section{REFERENCES}

1) Huh MJ, Lee D. A review of transitions to cochlear implants in Korea. Journal of Speech-Language \& Hearing Disorders 2009; 18(2):123-44.

2) Park SK. Newborn hearing loss and newborn hearing screening. Hanyang Med Rev 2015;35(2):72-7.

3) Kim LS, Lee MY, Heo MJ, Oh YJ. Long-term development of auditory performance in children with cochlear implants. Korean J Otolaryngol-Head Neck Surg 2002;45(1):18-21.

4) Lee MJ, Huh MJ, Jeong HI, Lee SH. Longitudinal study of ITMAIS questionnaires for children who may receive a cochlear implantation. Journal of Speech-Language \&Hearing Disorders 2009;18(4):151-64.

5) Waltzman S, Cohen NL, Gomolin R, Green J, Shapiro W, Brackett D, Zara C. Perception and production results in children implanted between 2 and 5 years of age. Adv Otorhinolaryngol 1997;52:17780.

6) Lee MJ, Jeong HI, Kim IH, Lee SH. Speech perception in children with bilateral cochlear implants. In: Lee WS, editor. Proceeding of 84th Annual Congress of Korean Society of OtorhinolaryngologyHead and Neck Surgery; 2010 April 23-25; Grand Hilton, Seoul. Mincom;2010. p.64.

7) Lee Y, Sim HS. Speech perception benefits of bilateral cochlear implantation for deaf children. Journal of Rehabilitation Research 2015;19(3):175-93.

8) Litovsky RY, Gordon K. Bilateral cochlear implants in children: Effects of auditory experience and deprivation on auditory perception. Hear Res 2016;338:76-87.

9) Song W, Lim D, Lee MS. Usage and satisfaction of devices among parents of children with cochlear implants. Audiology 2006;2(1): $72-7$.

10) Oh SH. Indications of cochlear implantation. Journal of Clinical Otolaryngology 2018;29(1):29-35.

11) Kim CS, Kim DK, Suh MW, Oh SH, Chang SO. Clinical outcomes of cochlear reimplantation due to device failure. Clin Exp Otorhinolaryngol 2008;1:10-4.

12) Lane C, Zimmerman K, Agrawal S, Parnes L. Cochlear implant failures and reimplantation: A 30-year analysis and literature review. Laryngoscope 2020;130:782-9.

13) Kim DY, Kim SS, Kim CH, Kim SC. Neonatal hearing screening in a neonatal intensive care unit using distortion product otoacoustic emissions. Korean J Pediatr 2006;49(5):507-12.

14) Heo SD. Prediction of cochlear implantation possibility in hearing aids users. Journal of Rehabilitation Welfare Engineering \& Assistive Technology 2019;13(1):27-32. 